\title{
The activity budgets of captive orangutan (Pongo pygmaeus) in two different Indonesian zoos
}

\author{
NURZAIDAH PUTRI DALIMUNTHE ${ }^{1}$, HADI SUKADI ALIKODRA ${ }^{2, \vartheta}$, ENTANG ISKANDAR $^{2}$, \\ SRI SUCI UTAMI ATMOKO \\ ${ }^{1}$ Doctoral Program in Primatology, Institut Pertanian Bogor. Jl. Lodaya II No. 5, Bogor 16151, West Java, Indonesia \\ ${ }^{2}$ Primatology Program, Institut Pertanian Bogor. Jl. Lodaya II No. 5, Bogor 16151, West Java, Indonesia. Tel. : +62-251-353386, Fax.: +62-251-360712, \\ vemail: halikodra.ha@gmail.com \\ ${ }^{3}$ Faculty of Biology, Universitas Nasional. Jl. Sawo Manila, Pejaten, Pasar Minggu, Jakarta Selatan 12520, Jakarta, Indonesia
}

Manuscript received: 22 October 2020. Revision accepted: 24 March 2021.

\begin{abstract}
Dalimunthe NP, Alikodra HS, Iskandar E, Atmoko SSU. 2021. The activity budgets of captive orangutan (Pongo pygmaeus) in two different Indonesian zoos. Biodiversitas 22: 1912-1919. In nature, orangutans spent most of the activity budgets for foraging. It is presumed that orangutan in captivity carries out different activities. This study aimed to investigate the activity of Bornean Orangutan (Pongo pygmaeus) in different zoos with different types of cage according to their design, enrichments, and diets. It was conducted at two different Indonesian zoos, namely Ragunan Zoo (TMR) and Taman Safari Indonesia (TSI). The study used a total of 11 orangutans. From each zoo, orangutan individuals from each zoo and each age and sex class (adult male, adult female, and juvenile/juvenile) were used in the present study. The activity budgets were compared between age-sexual classes, cage types, and weekday-holiday categories. Environmental enrichment analysis was also used. The total observation time in this study for each individual was 4,500 minutes. The adult male had more resting activity than other groups, while the juvenile group showed a higher percentage of social, moving, and feeding activities. It was also observed that there were different activity budgets between individuals in a separate cage and weekholiday groups. Overall, it was assumed that the difference in orangutan activity budgets was influenced by cage types, individual arrangements, and environmental enrichment. Meanwhile, a juvenile showed a higher percentage of enrichment using. Enrichment was influenced by cage type and individual arrangement.
\end{abstract}

Keywords: Captive orangutan, Activity budget, Indonesian zoo, Pongo pygmaeus, environmental enrichment

\section{INTRODUCTION}

The orangutan is the only great ape species out of Africa. It is only found in Sumatra and Borneo and recognized with three different species namely Pongo abelii, Pongo tapanuliensis, Pongo pygmaeus (Nater et al. 2017). In its natural habitat, the orangutan is typically a frugivorous and arboreal primate although Bornean orangutans were reported to be more adaptive to terrestriality (Loken et al. 2013). Orangutans are a primate species that is very dependent on the existence of tropical forests as their habitat, so that they are currently classified as endangered as a result of habitat fragmentation and illegal hunting (Ancrenaz et al. 2016; Singleton et al. 2016). Most of its daily activity budgets are for foraging, feeding, resting, and moving (Kanamori et al. 2010; Morrogh-bernard 2009). One of the influencing factors in orangutan activity budgets in the wild is the availability of food, especially fruit, as a consequence of energy use. When their habitats are changing, orangutans will increase their range to defend any resources available (Nayasilana et al. 2017). Meanwhile, orangutans in captivity are thought to have different activities compared to those in their natural habitats, especially in feeding behavior (Choo 2011). Captive orangutans do not need to forage actively or traveling for food; thus, they have more time for other activities (Crosby 2015).
Orangutan captivity, such as in zoos, aimed at protecting the species in an ex-situ manner. Ex-situ conservation effort is very appropriate and useful for endangered species and low population species in their natural habitat (Witzenberger and Hochkirch 2011). The zoo is designed to accommodate various interests and functions as a means of education, recreation, research, and conservation. In order to accommodate public concern regarding animal welfare, it is critical that zoos are engaged with the science of animal welfare (Maple and Bloomsmith 2018). Animal enclosures in several zoos are designed by zoo specialists, while at other places, they can be developed by a standard architect or a combination of both. Therefore, there is a concern that cages are not behaviorbased. If so, it is possible that animals cannot express their natural behavior as in their natural habitat. The zoo develops environmental enrichment techniques to address such concerns. Environmental enrichment aims to improve the animals' welfare through changes in management and breeding practices to increase behavioral choices (Ivana et al. 2017).

Apart from the cage's problem with its enrichment, another thing that is of concern is the diet of orangutans. Orangutan feeding is done by considering many factors. The diversity of primate diets depends on the species, stages of development, and environmental factors. Orangutans are primate species that predominantly eat 
fruits (frugivore). Besides, various research reports stated that orangutans also eat small insects and leaf sap, shoots, flowers (Morrogh-bernard 2009), rattans (Nayasilana et al. 2017), bamboo, ginger and soil (Kanamori et al. 2010). The availability of proper nutrition is primordial for orangutans in captivity because food has a significant effect on growth, reproduction, longevity, and ability to withstand diseases.

Information about activity budgets of captive orangutans is essential to assess animal welfare. Such information could be a necessary consideration in conservation management of captive orangutans, mostly in zoos. The present study aimed to compare orangutan activities in different zoos with different designs, environmental enrichments, and diets. The study also compared activity budgets between weekdays and holidays to assess the effect of visitor attendance on a captive orangutan in the zoo.

\section{MATERIALS AND METHODS}

\section{Time and Locations}

This study was conducted in ten months between May 2017 until February 2018 at two different Indonesian zoos, namely Taman Margasatwa Ragunan (TMR), Jakarta, Taman Safari Indonesia (TSI), Cisarua, and Bogor. Activity observation at TMR was conducted in three different cage types, i.e., enclosure, holding, and sleeping cages. Meanwhile, the observation was conducted in two different cage types at TSI, i.e., enclosure and sleeping cages.

\section{Subjects}

The subjects in this study were 11 individuals consisting of adult males (AM), adult females (AF), and juveniles (JUV). (See Table 1).

Table 1. The orangutan subjects in this study

\begin{tabular}{llll}
\hline No & Name & Sex & Age (years) \\
\hline TMR & & & \\
1 & Sane & Adult male & 24 \\
2 & Simon & Adult male & 24 \\
3 & Mona & Adult female & 24 \\
4 & Amida & Adult female & 24 \\
5 & Marsel & Juvenile male & 3.5 \\
TSI & & & \\
6 & Michel & Adult male & 24 \\
7 & Jhon & Adult male & 22 \\
8 & Kimba & Adult female & 21 \\
9 & Mega & Adult female & 23 \\
10 & Livia & Juvenile female & 6.5 \\
11 & Lindung & Juvenile male & 5 \\
\hline
\end{tabular}

\section{Captivity management}

During the observation, all individuals were placed in a variety of cage types and individual arrangements. There were three types of the cage, i.e., enclosure, sleeping, and holding cages (also known as inner cage was used as a daily cage for individuals who were not placed in the enclosure) (See Figure 1). The observation was adjusted with individual arrangement by zoo management.
Each zoo's enrichment item collection was analyzed and divided into five categories: physical, social, occupational, sensory, food (Table 2). Due to different specific enrichment items fitting into each category differed among the zoos, categories differentiating the things were broad by necessity. The use of enrichment was adapted to the situation of visitors, for example, the food enrichment was generally given if there were a lot of visitors during holidays. The other enrichment uses generally did not change according to the presence of visitors.

The individual arrangement is a way of placing individual orangutans in a cage in a zoo. During this study, the individual arrangements in both zoos consisted of several categories, namely single; mother-infant/juvenile; pairs, and group arrangements.

\section{Orangutan activity observation}

Orangutan activity observation was conducted following the Focal Animal Sampling method. Observations divided into two periods with individual recording duration of 15 minutes/hour. The morning period started at 09.00 and finished at 11.00. The evening period started at 13.00 and finished at 15.00. The total observation time for an individual was 2.5 hours per day. This procedure followed the Standard of Orangutan Activity Data with minimal activity observation duration of 90 minutes per day.

Table 2. List of enrichment across the zoos (TMR and TSI)

\begin{tabular}{|c|c|c|c|c|c|}
\hline \multirow[b]{2}{*}{ No } & \multicolumn{5}{|c|}{ Enrichment categories } \\
\hline & Physical & Social & $\begin{array}{l}\text { Occu } \\
\text { hal }\end{array}$ & $\begin{array}{l}\text { Sens } \\
\text { ory }\end{array}$ & Food \\
\hline \multicolumn{6}{|c|}{ TMR } \\
\hline \multicolumn{6}{|c|}{ Enclosure } \\
\hline & Shelter & - & Ropes & - & Browse \\
\hline & Bar & & Stairs & & Treats \\
\hline & Drum & & & & Pool \\
\hline & Tires & & & & \\
\hline & Swing & & & & \\
\hline \multicolumn{6}{|c|}{ Holding } \\
\hline & Tires & & & & \\
\hline & Shelter & & & & \\
\hline \multicolumn{6}{|c|}{ Sleeping cage } \\
\hline & Hammocks & & Rope & & \\
\hline \multicolumn{6}{|c|}{ TSI } \\
\hline \multicolumn{6}{|c|}{ Enclosure } \\
\hline & Shelter & Audio/music & Ropes & Browse & $\begin{array}{c}\text { Food } \\
\text { bars }\end{array}$ \\
\hline & Bar & & $\begin{array}{l}\text { Rope } \\
\text { ladder }\end{array}$ & Bell & Pool \\
\hline & Drum & & & & \\
\hline & Tires & & & & \\
\hline & Swing & & & & \\
\hline \multicolumn{6}{|c|}{ Sleeping cage } \\
\hline & & & & & Rope \\
\hline
\end{tabular}




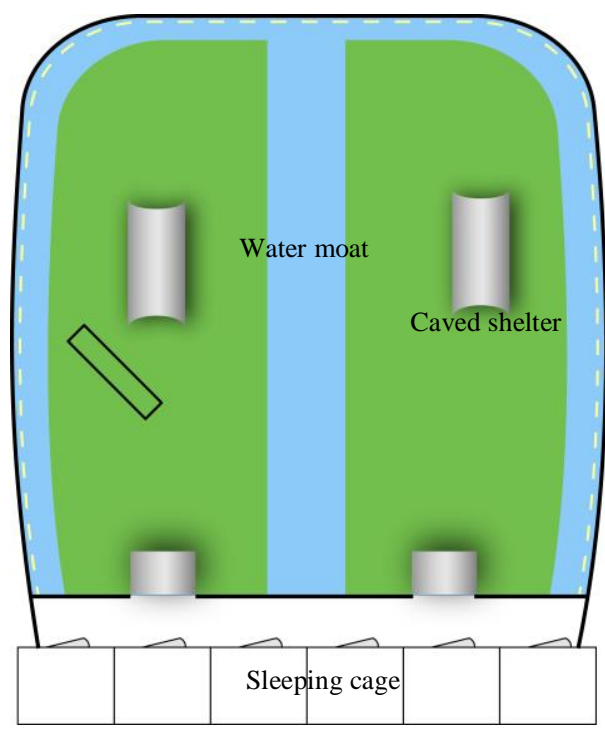

$\mathbf{A}$

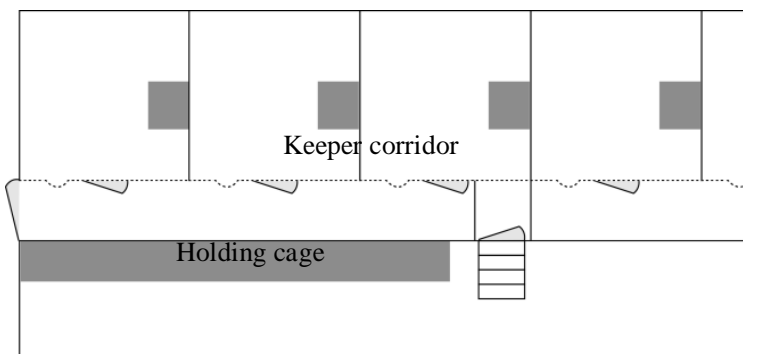

C

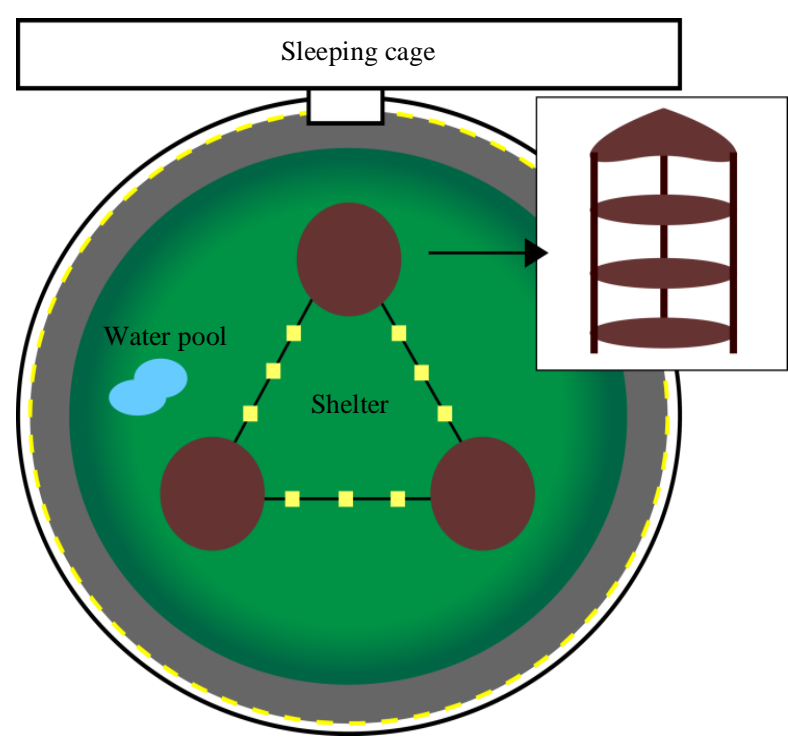

B

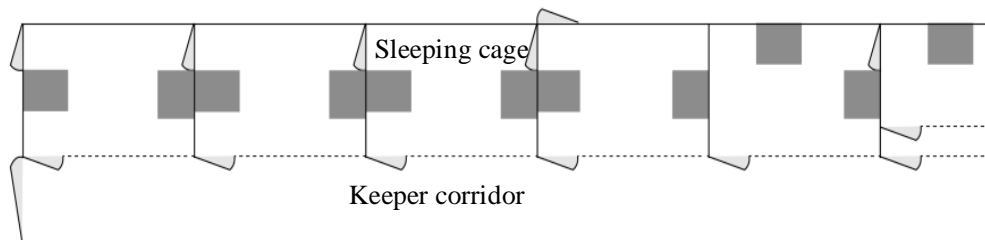

D

Figure 1. The orangutan cage sketches in two zoos: A. Enclosure and sleeping cage (TMR); B. Enclosure cage (TSI); C. Holding cage (TMR); D. Sleeping cage (TSI)

Table 3. Ethogram of orangutan main activities

\begin{tabular}{ll}
\hline Activities & Description \\
\hline Feeding & Ingestion and search for food or water \\
Resting & Sitting, standing or lying in still position \\
Social & Interacting with a partner \\
Moving & $\begin{array}{l}\text { Locomotion on and above the ground } \\
\text { Others }\end{array}$ \\
& $\begin{array}{l}\text { Mating and eliminating (defecation and } \\
\text { urination) }\end{array}$ \\
\hline
\end{tabular}

All four main activities, i.e., feeding, resting, social, and moving, were recorded daily. The descriptions of all activities can be seen in Table 3. Other activities, including mating and elimination (defecation and urination), were labeled 'others.' The percentage of activities was compared to three age-sex classes, i.e., AM, AF, and JUV. The study also compared activity budget differences between cage types and weekday-holiday. It also reported orangutan enrichment using and altitude of orangutan activity site across the zoos.

\section{Data analysis}

Orangutan activity and its components were quantitatively by providing information on the duration of their actions. The study also computed the percentage of occurrences of each activity from prevailing circumstances following the formula below.

$$
\mathrm{P}_{\mathrm{A}}=\text { (number of } \mathrm{A} / \text { total number of activities) } \mathrm{x} 100 \%
$$

The orangutan activity was analyzed with several variables namely age and sex groups, cage and individual arrangements, and weekdays-holidays. The parameter differences in orangutan activities were analyzed using ANOVAs with type of activities as dependent variable. Significant results used Tukey posthoc comparisons to determine significant pairwise differences. The KruskalWallis test, a post-hoc test with a significance level set at $5 \%$, was used where the data did not conform to the normal distribution or Levene's Test for Homogeneity of Variance produced a significant result. All of the data were displayed in the form of tables and graphs. 


\section{RESULTS AND DISCUSSION}

\section{The total duration of observation time}

The total duration of observation time in this study for each individual was 4,500 minutes, with an average observation time of 150 minutes per day. Observation of each individual's daily activities in this study was carried out in different types of cages (enclosure, sleeping cages, and holding cage) with different proportions (Table 4). In the TMR, there were three individuals, the daily activity observations of whom were carried out in just one type of cage, namely Sane (holding) and Amida and Marsel (enclosure). Meanwhile, two other individuals were observed in 2 kinds of cage, namely Simon (sleeping cage and enclosure) and Mona (sleeping cages and holding).

There were four individuals in TSI; the daily activity observations were carried out in just one type of cage, namely Jhon, Mega, and Kimba (enclosure) and Livia (sleeping cage). In comparison, two other individuals were observed in 2 types of cages, namely Michel and Lindung (Enclosure and sleeping cages).

\section{Captive orangutan activity budget}

\section{The variation between age and sex groups}

During this study, an observation of a total of 4,500 minutes was carried for each individual. Based on the age and sex categories, it appeared that there was a tendency that adult males did more resting activity than other groups, i.e., $55.11 \%$. Meanwhile, the percentage of social activity for adult females (12.38\%) was higher than that of adult males $(4.35 \%)$. The juvenile group had a higher rate of social action (30.94\%), moving (17.96\%), and feeding $(13.85 \%)$ compared to adult males and females (see Figure 2). The juvenile and adult females appeared to be more active in feeding than the adult male. The percentage of moving activity in the juvenile group appeared higher than that of adult orangutans.

Based on the ANOVA test, the percentage of daily activities for all activities appeared significantly different between three age and sex groups (INF, AF, and AM). This aspect can be seen from the ANOVA test results with a pvalue $<0.05$ (Table 5). The Post-hoc test showed that each age group had differences in resting, feeding, and social activities. The juvenile's percentage was lower than that of adult female and an adult male in resting activity. In feeding and social activities, the percentage of adult males was lower than that of adult females and juveniles. There was no difference in the percentage between adult males and adult females for moving activity, which was lower than that of the juvenile.

\section{The variation between cage types and individual arrangement}

Overall, the daily activity of orangutans in the enclosure cage showed a significant difference in the percentage of resting in the adult male group between TMR (Simon) and TSI (Jhon and Michel). Michel showed a lower resting percentage, i.e., $35.67 \%$, compared to Jhon (69.48\%) and Simon $(60.83 \%)$. Contrastly, Michel also showed a higher percentage of feeding, moving, and social activities compared to Jhon (TSI) and Simon (TMR) (See Figure 3). This result is related to Michel's aggressive character when placed in an enclosure cage with other individuals. Michel seemed to move more to catch up with other individuals (Kimba was placed in pairs in the same enclosure cage). This aspect is the reason why Michel was rarely put in the enclosure cage. The difference in individual character was also seen in adult females at TSI, which showed a striking difference in the percentage of resting between Mega $(52.19 \%)$ and Kimba (34.62\%). In the juvenile group, individuals in TSI appeared to have lower percentage of resting activity (Lindung, i.e. 15.5\%) compared to individuals in TMR (Marsel, namely 23.29\%).

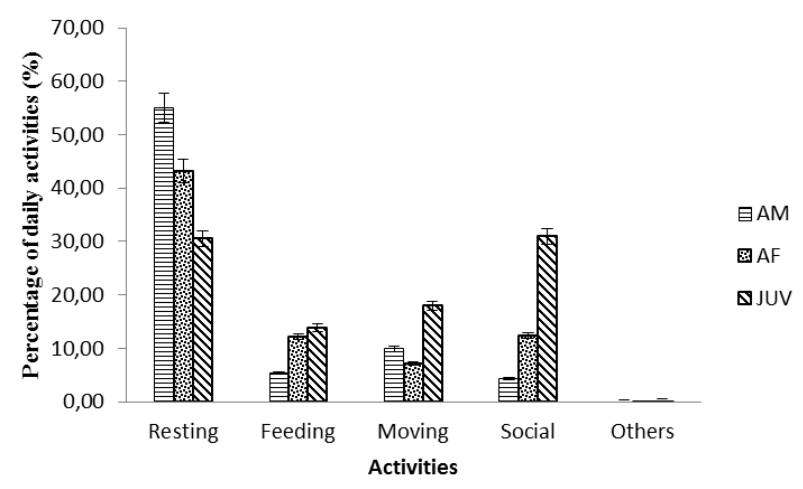

Figure 2. Activity budgets of captive orangutans between different age-sex classes (AM: adult male, AF: adult female, JUV: juvenile).

Table 4. The total duration time of observation for each individual in different type of cages

\begin{tabular}{ccccc}
\hline No & $\begin{array}{c}\text { Individu } \\
\text { als }\end{array}$ & $\begin{array}{c}\text { Age-sex } \\
\text { categories }\end{array}$ & Ebservation duration (minutes) \\
\cline { 4 - 5 } & Enclosure & $\begin{array}{c}\text { Sleeping } \\
\text { cage }\end{array}$ & $\begin{array}{c}\text { Holding } \\
\text { cage }\end{array}$ \\
\hline
\end{tabular}

\section{TMR}

$\begin{array}{lllccc}1 & \text { Sane } & \text { Adult male } & - & - & 4,500 \\ 2 & \text { Simon } & \text { Adult male } & 3,000 & 1,500 & - \\ 3 & \text { Mona } & \text { Adult female } & - & 3,000 & 1,500 \\ 4 & \text { Amida } & \text { Adult female } & 4,500 & - & - \\ 5 & \text { Marsel } & \text { Juvenile } & 4,500 & - & -\end{array}$

TSI

\begin{tabular}{lllccc}
1 & Jhon & Adult male & 4,500 & - & - \\
2 & Michel & Adult male & 750 & 3,750 & - \\
3 & Mega & Adult female & 4,500 & - & - \\
4 & Kimba & Adult female & 4,500 & - & - \\
5 & Lindung & Juvenile & 1,050 & 3,450 & - \\
6 & Livia & Juvenile & - & 4,500 & - \\
\hline
\end{tabular}

Note: TMR: Taman Margasatwa Ragunan, Jakarta. TSI: Taman Safari Indonesia, Cisarua, Bogor

Table 5. The difference of daily activity percentage between age and sex groups

\begin{tabular}{llcc}
\hline Categories & Activities & ANOVA & Post-hoc \\
\cline { 1 - 3 } Age and & Resting & $\mathrm{F}=201.21, \mathrm{p}<0.05$ & $\mathrm{INF}<\mathrm{AF}<\mathrm{AM}$
\end{tabular}




\begin{tabular}{llll}
\hline sex groups & Feeding & $\mathrm{F}=6.92, \mathrm{p}<0.05$ & $\mathrm{AM}<\mathrm{AF}<\mathrm{JUV}$ \\
& Moving & $\mathrm{F}=28.132, \mathrm{p}<0.05$ & $\mathrm{AM}, \mathrm{AF}<\mathrm{JUV}$ \\
& Social & $\mathrm{F}=265.41, \mathrm{p}<0.05$ & $\mathrm{AM}<\mathrm{AF}<\mathrm{JUV}$ \\
\hline
\end{tabular}

Note: AM (adult male), AF (adult female), JUV (juvenile)

In the sleeping cage, it was seen that in the adult male group in TMR (Simon) and TSI (Michel), there was a striking difference in the percentage of resting (Figure 4). Michel showed a lower percentage of resting (44.89\%) compared to Simon (72.59\%). Contrastly, Michel had a higher percentage of feeding, moving and social activities compared to Simon.

\section{Variation between weekdays-holidays}

At TSI, there was a difference between resting in adult male individuals (Jhon $73.20 \%$ and Michel $41.56 \%$ ) on weekdays, which was higher than that of holidays (Jhon $50.89 \%$ and Michel 36.50\%). In adult female individuals, there was a difference in the percentage of resting on weekdays, which was lower (Mega, 50.13\%) than that on holidays (Mega, 62.44\%) (Figure 5). In feeding and moving activities, it can be seen that there were higher percentages on holidays compared to weekdays.

At the TMR, an adult male (Simon) showed a higher percentage of resting on weekdays $(66.03 \%)$ than holidays $(54.72 \%)$. For adult females (Amida), there was a lower percentage of resting on weekdays $(56.40 \%)$ compared to holidays $(62 \%)$. Contrastly, all individuals showed a higher percentage of feeding on holidays than on weekdays (Figure 6).

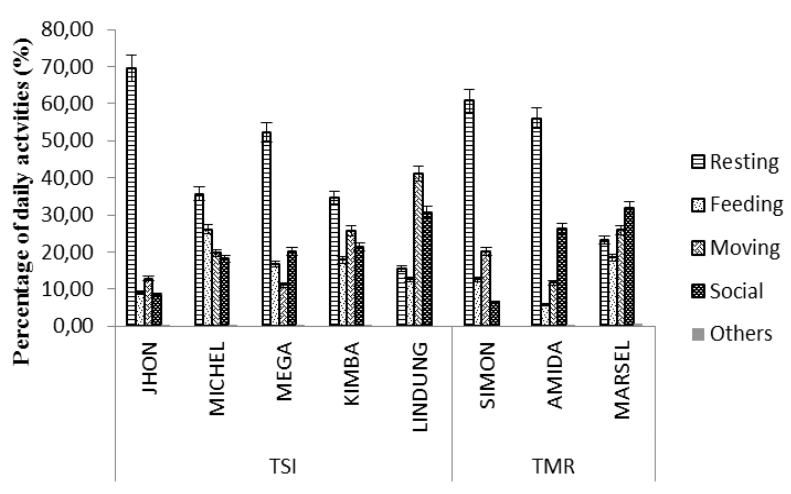

Figure 3. Percentage of orangutan daily activities in enclosure cage in TSI and TMR.

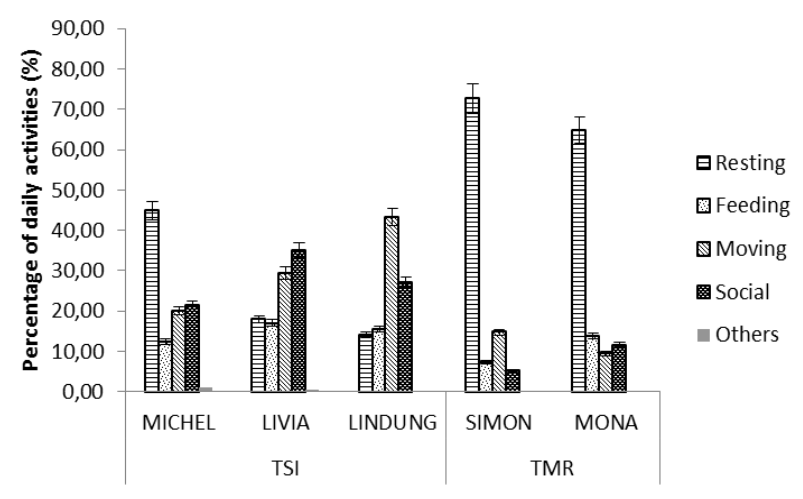

Figure 4. Percentage of orangutan daily activities in sleeping cage in TSI and TMR

\section{Using of environmental enrichment}

Generally, the use of environmental enrichment in juveniles was higher than that of other categories (adult male and adult female), both in type and usage frequencies. Lindung (juvenile) was the highest in terms of the number of enrichment per day (3.50) and usage frequency per day (18.67). Meanwhile, Mona (adult female) had the lowest in the same terms $(0.58$ and 0.58$)$. That result was found when Lindung was placed in an enclosure cage and Mona in a holding cage. When Lindung was placed in a sleeping cage, the results were lower (1.21 and 8.92). In the case of Mona, the results were slightly higher (0.61 and 0.83). (Table 6).

\section{Discussion}

The study reported the activity budgets of 11 individuals in three age-sex classes in two different zoos. It found that age-sex classes showed different activity budgets. The adult male showed more resting activity, while the juvenile showed more moving and social activities. The result was similar to activity budgets in their natural habitat where males (especially flanged males) are found to show the least moving activity than most age-sex classes (Morrogh-Bernard 2009).

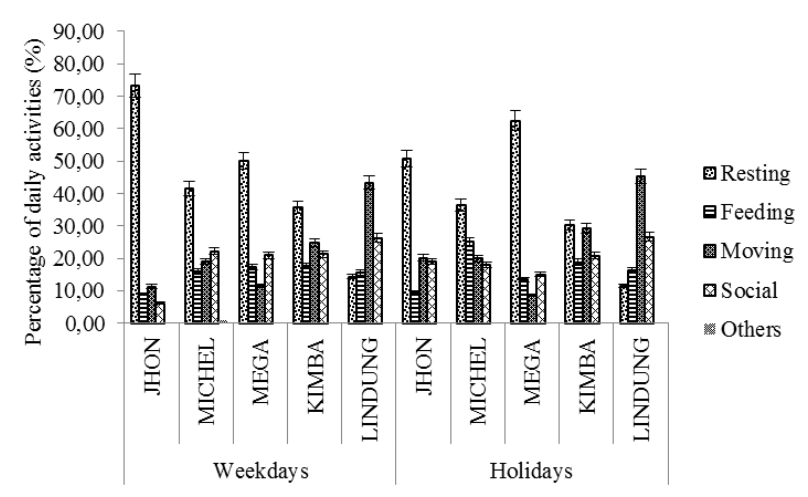

Figure 5. Percentage of orangutan daily activities in TSI between weekdays and holidays 


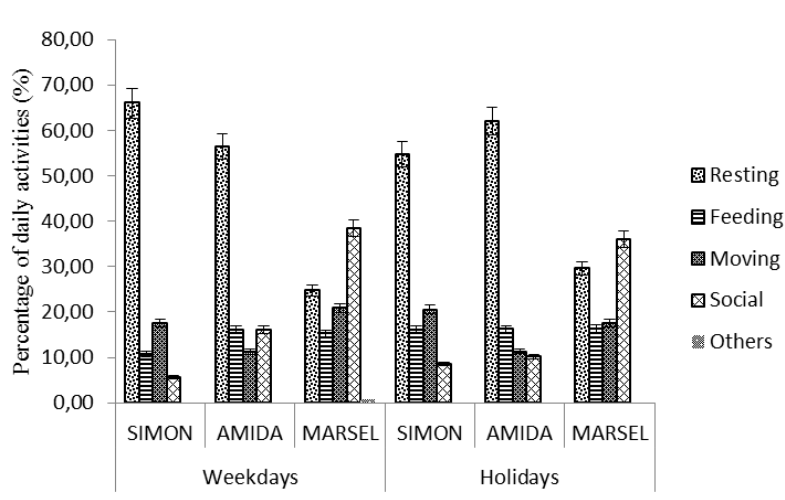

Figure 6. Percentage of orangutan daily activities in TMR between weekdays and holidays

Tabel 6. The use of environmental enrichment of orangutans in TMR and TSI

\begin{tabular}{|c|c|c|c|}
\hline No & Individual & $\begin{array}{c}\text { Average items } \\
\text { (perdays) }\end{array}$ & $\begin{array}{l}\text { Using frequencies } \\
\text { (perdays) }\end{array}$ \\
\hline \multicolumn{4}{|c|}{ Holding TMR } \\
\hline 1 & Sane $^{1}$ & 1.30 & 1.70 \\
\hline 2 & Mona $^{2}$ & 0.61 & 0.83 \\
\hline \multicolumn{4}{|c|}{ Enclosure TMR } \\
\hline 1 & Simon $^{1}$ & 1.88 & 2.24 \\
\hline 2 & Amida $^{2 *}$ & 0.87 & 1.03 \\
\hline 3 & Marsel $^{2 *}$ & 2.37 & 4.20 \\
\hline \multicolumn{4}{|c|}{ Sleeping cage TMR } \\
\hline 1 & Simon $^{1}$ & 0.85 & 1.23 \\
\hline 2 & Mona $^{2}$ & 0.58 & 0.58 \\
\hline \multicolumn{4}{|c|}{ Enclosure TSI } \\
\hline 1 & Jhon $^{4}$ & 1.60 & 2.06 \\
\hline 2 & Michel $^{3}$ & 3.25 & 9.50 \\
\hline 3 & $\mathrm{Mega}^{4}$ & 1.53 & 2.26 \\
\hline 4 & $\mathrm{Kimba}^{3,4}$ & 2.10 & 7.20 \\
\hline 5 & Lindung 4 & 3.50 & 18.67 \\
\hline \multicolumn{4}{|c|}{ Sleeping cage TSI } \\
\hline 1 & Michel $^{1}$ & 0.96 & 3.33 \\
\hline 2 & Lindung $^{3}$ & 1.21 & 8.92 \\
\hline 3 & Livia $^{3}$ & 1.00 & 4.06 \\
\hline
\end{tabular}

Note: 1: single, 2: mother-infant (not obeserved), $2 *:$ motherjuvenile, 3: paired, 4: group, bold $=$ highest, underline $=$ lowest.

Daily percentages of time spent in each activity varied between age classes, social structure, and fruiting season. As an example, orangutan moving activity positively correlated with the availability of fruit and being social can increase active period length (Morrogh-Bernard 2009; (Kanamori et al., 2010). A juvenile naturally shows a higher percentage of social activity, especially playing with other juvenile individuals. At the age of 1 year, Orangutans seemed to be doing more playing activities on their own, but this would increase until around 6 years old. Orangutan activity at the age of 1 year is dominated by resting, representing up to $70 \%$, which will decrease with age. The same thing was seen in feeding activity, which would increase with age $(7-22 \%$ at age 1 year to $30 \%$ at age 3 years) (Mendonca et al. 2016). Another result showed that one orangutans infant in Dublin Zoo spent $43.4 \%$ for resting (when its mother alive) but fell significantly to
28.9\% without its mother (Whilde and Marples 2010). Meanwhile, in reintroduction orangutans, the most significant activity was feeding $(53.5 \%-62.05 \%)$ and resting (19.52\%-64.67\%) (Basalamah et al. 2018; Bani et al. 2018).

From these results, it can be seen that there was a difference in the percentage of adult orangutan activity in zoos and a wild orangutan. The main difference was seen in orangutan's resting activity in zoos, which was much higher than that of wild orangutans. Otherwise, the percentages of feeding and moving activities in a zoo are lower than those of wild orangutans. In nature, orangutans spent about $50-60 \%$ of their time feeding and foraging, 25$35 \%$ for resting, and $10-15 \%$ for moving (Kanamori et al. 2010; Morrogh-Bernard et al. 2009). Although the main factor affecting the percentage of wild orangutan daily activity is the availability of food, captive orangutan does not need to spend a lot of time for food foraging. On average, captive orangutans in zoos spend only $19-25 \%$ of their time feeding (Choo 2011). Orangutans in captivity will devote more time to other activities (Crosby 2015), especially for resting or idling (Choo 2011).

In this study, the other possible factors affecting the high percentage of social activity, moving, and feeding were the type of cage and individual arrangement. In TMR, the orangutan has usually placed a single individual in one enclosure. At TSI, several adult female individuals were put together with one adult male in the same enclosure (sometimes including juvenile). The study found related data showing the percentage of social activity for an adult male in TSI, which was higher than that in TMR. The juveniles, Livia and Lindung (TSI), were more often placed in a sleeping cage with individual arrangements in pairs. Meanwhile, Marsel (TMR) was placed with its mother Amida in an enclosure cage for all observation time. Lindung and Livia appeared to be doing more social activity, especially playing.

Other than for these reasons, the study also found that visitors' presence affected several individuals' activity budgets, as seen in individual Simon. This confiscated orangutan looks very enthusiastic with visitors' company because it has experience interacting with a human. The increase in the percentage of feeding activity was probably due to visitors' behavior providing feed to the orangutan, even though the zoo management has prohibited this. This finding was in line with previous study showed that orangutan in care actively observes their surrounding and interested with beyond their enclosure. Captive orangutans were seen begging and looking to the closed visitors. The presence of visitors i.e. large crowds, visitors with food, visitors who were looking or taking photographs, and visitors who were close by were known to affect orangutan behavior (Choo et al. 2011). Bloomfield et al. (2015) suggested that orangutans have a preference to position themselves to face the window of the visitor viewing area. Captive orangutans also known to actively seek a novelty and are highly exploratory and innovative and showed no neophobia to novel objects (van Schaik et al. 2015). Orangutans also found to have larger innovation repertoires in comparison with their wild counterparts (Lehner et al. 
2010). Forss et al. (2015) found that captive orangutans were more responsive to novel objects than their wild counterparts. The main explanation was referred to the time constraints of response to new objects (Forss et al. 2015). In captive animals, excess energy (Benson-Amram et al. 2013), lack of predator pressure, and foraging challenges were known allowing the animals for more exploration (Forss et al. 2015).

During the observation, the study that both zoos (TMR and TSI) provided different environmental enrichment (Table 2). The presence of that enrichment presumably affected orangutan activity. TMR and TSI adopted outdoortype cages with plants such as trees, shrubs, and grasses. Sometimes, they provided additional feed enrichment on holidays when the number of visitors is overwhelming. This action was done to make orangutans move more than usual and attract visitors' attention. The use of enrichment can increase the frequency of feeding, moving, and social activities and, at the same time, decrease the frequency of resting activity. Choo (2011) found captive orangutans spent most of their time in trees, nets, platforms, logs, and vines sequentially. Crosby (2015) also found a significant impact of enrichment categories on behaviors on an individual basis. Non-natural enrichment was associated with more affiliative social interaction, more time spent in proximity of conspecifics, and more head covering instances. Her result also revealed no difference in outcomes when non-natural versus natural enrichment items were offered and suggested that zoos feel less constrained concerning naturalistic-only enrichment policies in exhibiting and proposing that it is essential to consider the significant effects of natural properties on individual behaviors.

The findings also showed that orangutans were fed before being placed in the enclosure/exhibit. Both TMR and TSI provided food enrichment that is different in types and numbers. TMR relatively provided more amount of food for enrichment, especially on holidays. It was assumed that this fact influenced orangutan activity budgets. It corresponds to the finding that adult males (Simon) placed in the enclosure had higher 'feeding' percentages during the holiday. Based on a previous study, orangutans in TSI and TMR generally obtained energy intake exceeding the daily needs of wild orangutans (Dalimunthe et al. 2020).

In terms of enrichment usage, it was found that the highest use of enrichment was for playing, moving, and feeding purposes in juveniles. Different results were found in adult males and females, where they used enrichment more for moving and feeding purposes. The variation was seen in two variables, i.e., cage type (enclosure, sleeping cage, holding cage) and individual arrangement (single/paired/ group/ mother-juvenile or juvenile). An individual with the same age-sex category placed together with other individuals (groups) appeared to use environmental enrichment in terms of number and frequency compared to age-sex types with different individual arrangements (single/paired/ mother-juvenile). The presence of environmental enrichment seemed to stimulate orangutans to more moving. This result was in line with previous reports according to which physical properties of the enrichment of the enclosure environment can influence animal behavior. Captive orangutans can maintain their movement level as their wild counterparts because of the presence of naturalistic design and large size of orangutans enclosure (Pearson et al. 2010). Shariman and Ruppert (2017) also found that food enrichment can increase foraging time significantly and decreases resting of captive orangutans.

Although enrichment is often used to reduce stereotypical behavior in captive animals, enrichment is being used increasingly more often to create a rich and stimulating environment and can improve captive animal welfare (Whitehouse et al. 2013). Nowadays, environmental enrichment plays a vital role in modern zoos (Swaisgood and Shepherdson 2005) and is considered standard practice, and is essential for the management of modern zoo animals (Clark 2017). Furthermore, the specificity of environmental enrichment (size, texture, and resistance) is a significant concern (Crosby 2015). In practice, enrichment commonly serves the need for food and rare to stimulate a high level of cognitive skill (Clark 2011). It is exceptional if the enrichments are not related to extrinsic food rewards (Clark 2017). Based on our result, such practices were still being carried out in the zoos where this research is conducted. Therefore, improvement and innovation efforts are needed in the provision of enrichment in orangutan cages as in chimpanzees (Pan troglodytes) practice, known as cognitive enrichment (Clark and Smith 2013). The use of effective enrichment in the long term also must be a dynamic and goal-oriented process where the stimuli given are changed regularly and there are new stimuli given periodically (Young et al. 2020) so that the animal does not lose interest in the given enrichment (Vasconcellos et al. 2012). Another thing to consider is that captive animals may react to enrichment differently, both between species and between animals of different personalities (Ortiz et al. 2017).

In conclusion, the study found that adult male spends most of their activity budgets for resting. Juvenile appears to be more social than any other age-sex classes. It also found that the activity budget of captive orangutans was affected by cage type, individual arrangement, and environmental enrichment. The use of ecological enrichment also was influenced by cage type and unique arrangement.

\section{ACKNOWLEDGEMENTS}

The authors declare that there were no conflicts of interest. This research was supported by the BPPDN grant, Ministry of Research, Technology, and Higher Education of Indonesia, and SEAMEO BIOTROP, Bogor. The authors would also like to express their special thanks to Taman Margasatwa Ragunan (Ragunan Zoo) and Taman Safari Indonesia, who allowed and supported this research in their facilities; and also all keepers and administrators at both research locations. 


\section{REFERENCES}

Ancrenaz M, Gumal M, Marshall AJ, Meijaard E, Wich SA \& Husson S 2016. Pongo pygmaeus. In the IUCN Red List of Threatened Species: E.t17975a17966347. International Union for Conservation of Nature, Gland, Switzerland, and Cambridge, UK. DOI: 10.2305/iucn.uk. 2016-1.rlts.t17975a17966347.en

Bani SN, Perwitasari-Farajallah D, Utami-Atmoko SS, Sihite J. 2018 Adaptation behavior of Bornean Orangutan (Pongo pygmaeus morio) reintroduction in Kehje Sewen Forest, East Kalimantan, Indonesia. Biodiversitas 19 (3): 989-996.

Basalamah F, Utami-Atmoko ss, Perwitasari-Farajallah D, Qayim I, Sihite J, van noordwijk M, willems E, van Schaik CP. 2018. Monitoring orangutan reintroduction: Results of activity budgets, diets, vertical use and associations during the first year post-release in Kehje Sewen Forest, East Kalimantan, Indonesia. Biodiversitas 19 (2): 689-700.

Benson-Amram S, Weldele ML, Holekamp KE. 2013. A comparison of innovative problem-solving abilities between wild and captive spotted hyaenas, Crocuta crocuta. Anim Behav 85: 349-356.

Bloomfield RC, Gillespie GR, Kerswell KJ, Butler KL, Hemsworth PH. 2015. Effect of partial covering of the visitor viewing area window on positioning and orientation of zoo orangutans: A Preference Test. Zoo Biol 34: 223-229.

Choo Y, Todd PA, Li D. 2011. Visitor effects on zoo orangutans in two novel, naturalistic enclosures. Appl Anim Behav Sci. 133: 78-86.

Choo YT. 2011. Orangutan Behaviour in Captivity: Activity Budgets, Enclosure Use and The Visitor Effect. [Thesis]. National University, Singapore.

Clark FE \& Smith LJ. 2013. Effect of a cognitive challenge device containing food and non-food rewards on chimpanzee well-being. Am J Primatol 75: 807-816.

Clark FE. 2011. Great ape cognition and captive care: Can cognitive challenges enhance well-being? Appl Anim Behav Sci 135: 112.

Clark FE. 2017. Cognitive enrichment and welfare: current approaches and future directions. Anim Behav Cogn 4 (1): 52-71.

Crosby K. 2015. Effects of natural vs non-natural enrichment items on captive orangutan behavior. [Thesis]. Ball State University, Muncie, Indiana, USA.

Dalimunthe NP, Alikodra HS, Iskandar E, Utami-Atmoko SS. 2020 Manajemen Pakan dan Pemenuhan Nutrisi Orangutan Kalimantan (Pongo pygmaeus). di Taman Safari Indonesia dan Taman Margasatwa Ragunan. J Biol Indon 16 (1): 57-66. [Indonesian]

Forss SIF, Schuppli C, Haiden D, Zweifel N, van Schaik CP. 2015 Contrasting responses to novelty by wild and captive orangutans. Am J Primatol 77: 1109-1121. DOI: 10.1002/ajp.22445.

Ivana G, Martin H, Jitka S. 2017. Environmental enrichment in the awareness of zoo visitors and the general public. Ann Res Rev Biol 20 (2): $1-5$

Kanamori T, Kuze N, Bernard H, Malim TP, Kohshima S. 2010. Feeding ecology of Bornean orangutans (Pongo pygmaeus morio) in Danum Valley, Sabah, Malaysia: A 3-year record including two mast fruiting. Am J Primatol 72: 820-840.

Lehner SR, Burkart JM, van Schaik CP. 2010. An evaluation of the geographic method for recognizing innovations in nature, using zoo orangutans. Primates. 51: 101-118. DOI: 10.1007/s10329-009-01848.
Loken B, Spehar SS, Rayadin Y. 2013. Terrestriality in the Bornean Orangutan (Pongo pygmaeus morio) and implications for their ecology and conservation. Am J Primatol 75: 1129-1138.

Maple TL, Bloomsmith MA. 2018. Introduction: The science and practice of optimal animal welfare. Behav Process 156: 1-2.

Mendonca RS, Kanamori T, Kuze N, Hayashi M, Bernard H, Matsuzawa T. 2016. Development and behaviour of wild infant-juvenile East Bornean orangutans (Pongo pygmaeus morio) in Danum Valley. Primates 58 (1): 211-224. DOI 10.1007/s10329-016-0567-6.

Morrogh-Bernard HC et al. 2009. Orangutan activity budgets and diet. In: Wich SA, Atmoko SSU, Setia TM, van Schaik CP (eds.). Orangutans: Geographic variation in behavioral ecology and conservation. Oxford University Press, Oxford.

Nater A, Maja P. Mattle-Greminger, Nurcahyo A, Nowak MG, Manuel M, Desai T, Groves C, Pybus M, Sonay TB, et al. 2017. Morphometric, Behavioral, and Genomic Evidence for a New Orangutan Species. Curr Biol 27 (22): 3487-3498

Nayasilana IN, Hadisusanto S, Wijayanto H, Utami-Atmoko SS, Prasetyao D, Sihite J, Van Schaik CP. 2017. Behavioral ecology of reintroduced Orangutans in the Bukit Batikap, Central Kalimantan, Indonesia. Biodiversitas 18 (3): 875-886.

Ortiz ST, MaxwellA and Hansen KA. 2017. Research as an enrichment tool to improve welfare in captive animals. Anim Husb Dairy Vet Sci 2 (1): $1-6$.

Pearson EL, Davis JM, Litchfield CA. 2010. A case study of orangutan and siamang behavior within a mixed-species zoo exhibit. J Appl Anim Welf Sci 13 (4): 330-346.

Shariman PSMA, Ruppert N. 2017. Effect of environmental enrichment on activities of captive orangutans at Taiping Zoo, Malaysia. Malay Nat J 69 (4): 327-335

Singleton I, Wich SA., Nowak M, Usher G. 2016. Pongo abelii. In The IUCN Red List of Threatened Species: e.T39780A102329901. International Union for Conservation of Nature, Gland, Switzerland, and Cambridge, United Kingdom.

Swaisgood RR, Shepherdson DJ. 2005. Scientific approaches to enrichment and stereotypies in zoo animals: What's been done and where should we go next? Zoo Biol 24: 499-518.

van Schaik CP, Burkart J, Damerius L, Forss SIF, Koops K, van Noordwijk MA and Schuppli C. 2015. The reluctant innovator: orangutans and the phylogeny of creativity. Phil Trans R Soc B 371: 20150183. DOI: $10.1098 /$ rstb.2015.0183.

Vasconcellos AS, Adania CH, Ades C. 2012. Contrafreeloading in maned wolves: implications for their management and welfare. Appl Anim Behav Sci 140: 85-91. DOI: 10.1016/j. applanim.2012.04.012.

Whilde J, Marples N. 2010. The behavior of a zoo-housed infant orangutan after the death of its mother. Zoo Biol 29: 1-7.

Whitehouse J, Micheletta J, Powell1 LE, Bordier C, Waller BM. 2013. The impact of cognitive testing on the welfare of group-housed primates. PLoS One 8 (11): e78308. DOI: 10.1371/journal.pone.0078308.

Witzenberger KA \& Hochkirch A. 2011. Ex-situ conservation genetics: a review of molecular studies on the genetic consequences of captive breeding programmes for endangered animal species. Biodivers Conserv 20: 1843-1861. DOI 10.1007/s10531-011-0074-4.

Young RJ, de Azevedo CS, Cipreste CF. 2020. Environmental Enrichment: The Creation of Opportunities for Informal Learning. In: Melfi VA, Dorey DR, Ward SJ (eds.). Zoo Animal Learning and Training. John Wiley \& Sons, New Jersey. 